\title{
Simulasi Pembebanan Komponen Bender pada Desain Mesin Begel Fabricator Menggunakan Software Autodesk Inventor 2020
}

\author{
Satriawan Dini Hariyanto ${ }^{1 *}$, Wikan Kurniawan² \\ 1Jurusan Teknik Mesin, Fakultas Teknologi Industri, Institut Sains \& Teknologi AKPRIND \\ Yogyakarta, Jl. Kalisahak No.28, Klitren, Gondokusuman, Kota Yogyakarta 55222 \\ ${ }^{2}$ Rumah Sakit Akademik Universitas Gadjah Mada, Jl. Kabupaten (Lingkar Utara), \\ Kronggahan, Trihanggo, Gamping, Sleman, Yogyakarta 55291
}

Penulis korespondensi: *satriawan@akprind.ac.id

Histori artikel: diserahkan 22 Maret 2021, direviu 26 Maret 2021, direvisi 07 April 2021

\begin{abstract}
Stress analysis of the bender components in the design of the begel fabricator machine was carried out using FEA (Finite Element Analysis) with three variations of the constituent material parameters, namely 6061 aluminum, mild steel, and cast iron with a modulus of elasticity of $68.9 \mathrm{GPa}, 220 \mathrm{GPa}, 120.5 \mathrm{GPa}$, respectively. The test is carried out by a loading parameter $2520 \mathrm{MPa}$ and fixed constraint. The maximum von misses stress and displacement obtained for each material parameter components using aluminum, mild steel, and cast iron are $17.78 \mathrm{MPa} ; 0.00765$, $17.49 \mathrm{MPa} ; 0.00229,17.62 \mathrm{MPa} ; 0.00427$ respectively.
\end{abstract}

Keywords: Begel, Bender, FEA, Begel fabricator machine

DOI : https://doi.org/10.18196/jqt.v2i2.11581

WEB : https://journal.umy.ac.id/index.php/qt/article/view/11581

\section{PENDAHULUAN}

Rebar (reinforced bar) atau baja tulangan merupakan komponen yang banyak digunakan pada bidang konstruksi. Dalam penggunaannya rebar terbagi menjadi dua jenis yaitu baja tulangan polos dan baja tulangan sirip. Rebar banyak dimanfaatkan sebagai komponen utama dalam pembuatan begel. Begel adalah bagian penyusun konstruksi baja yang digunakan sebagai komponen penahan beban geser yang terjadi pada struktur tulangan kolom beton. Pada umumnya begel dibuat dari rebar yang melalui proses penekukan (bending) pada sudut tertentu sesuai standar SNI 03-2847-2002. Metode fabrikasi begel dapat dilakukan dengan menggunakan cara manual dan mesin (begel fabricator). Penelitian yang dilakukan oleh (Deepu et al., 2018) menunjukkan besarnya gaya yang dibutuhkan pada proses bending baja tulangan berdiameter $8 \mathrm{~mm}$ dalam proses pembuatan begel adalah sebesar 196,13 N dengan momen 78,4 N.m untuk sudut penekukan $90^{\circ}$. Ditinjau dari konfigurasi gerakan pada proses bending, metode fabrikasi begel menggunakan mesin dapat dilakukan secara langsung dengan memanfaatkan gearbox dan komponen bender untuk menaikkan torsi poros penekuk baja tulangan. Selain itu, konfigurasi lainnya pada mesin begel fabricator adalah dengan berbasis pada konversi gerak rotasi menjadi gerak translasi. Komponen yang bergerak secara translasi digunakan untuk menekan material baja tulangan. Kelebihan mesin begel fabricator dengan sistem gerakan translasi antara lain proses pembuatannya lebih mudah dan konstruksinya lebih sederhana. Akan tetapi kelemahan pada mesin jenis ini terletak pada rugi-rugi mekanis yang lebih tinggi akibat adanya konversi gerakan rotasi menjadi translasi, dimensi rangka mesin yang lebih besar, dan dimensi begel yang mampu dihasilkan terbatas. Kelebihan mesin begel fabricator dengan konfigurasi langsung adalah alur proses fabrikasi yang lebih pendek sehingga rugi-rugi mekanis yang timbul lebih rendah, perawatan lebih mudah, dan fleksibilitas dimensi begel yang mampu dibuat lebih banyak karena menggunakan motor listrik yang dapat dikontrol dengan mekanisme kontroller elektronik. Akan tetapi memiliki kelemahan dari jumlah produksi begel yang dihasilkan lebih rendah dibanding jenis mesin berkonfigurasi gerakan translasi. Komponen 
yang berpotensi mengalami kegagalan pada proses bending pada mesin begel fabricator terletak pada komponen bender (Shah et al., 2019). Bender adalah komponen yang mengalami kontak langsung dengan permukan baja tulangan saat terjadi proses bending. Komponen ini mengalami pembebanan secara berulang pada setiap gerakan penekukan yang terjadi pada proses fabrikasi begel.

Penelitian ini bertujuan untuk mengevaluasi desain 3D komponen bender menggunakan software Autodesk Inventor 2020 yang memiliki keunggulan dapat menganalisis tegangan von misss dengan fitur FEA (Finite Element Analysis) didalamnya (Hariyanto et al., 2020). Variasi material penysusun komponen bender terdiri dari aluminium 6061, mild steel, dan besi tuang (cast iron) dilakukan untuk mengetahui distribusi tegangan yang terjadi pada tiap jenis material.

\section{METODE}

Tahapan analisis pada metode elemen hingga (FEA) terdiri dari tiga tahapan, yaitu preprocessing, processing, dan post-processing. Tahapan pre-processing merupakan tahap pembuatan desain tiga dimensi dalam format file ".ipt" (Gambar 1). Tahap processing meliputi penentuan lokasi pembebanan, penempatan constraint, penentuan besarnya gaya pembebanan, pengaturan mesh, dan running analysis. Tahap post processing merupakan tahapan terakhir yang berhubungan dengan intrepretasi data hasil simulasi FEA yang telah dilakukan. Pada tahap post processing diperoleh data berupa nilai tegangan von Misses, safety factor, dan besar displacement yang terjadi pada desain bender. Pemodelan FEA menggunakan software autodesk inventor 2020 merupakan pendekatan sifat fisik komponen struktur dengan asumsi material dalam model bersifat homogen dengan respon linier terhadap tegangan (Afolabi et al., 2019).

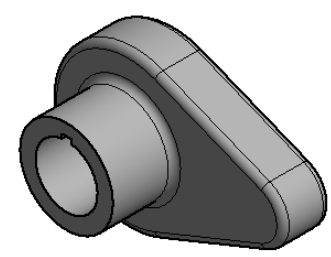

GAMBAR 1. Desain komponen bender dalam format file ".ipt"
Komponen bender dirancang memiliki dimensi panjang $75 \mathrm{~mm}$ dan lebar $50 \mathrm{~mm}$ seperti ditunjukkan pada Gambar 2. Pada instalasi mesin begel fabricator, bender dikopel dengan poros berdiameter $20 \mathrm{~mm}$ yang terhubung dengan gearbox dengan sumber penggerak motor listrik DC. Gerakan bender diatur oleh motor listrik yang terhubung dengan pengendali elektronik berbasis mikrokontroller.
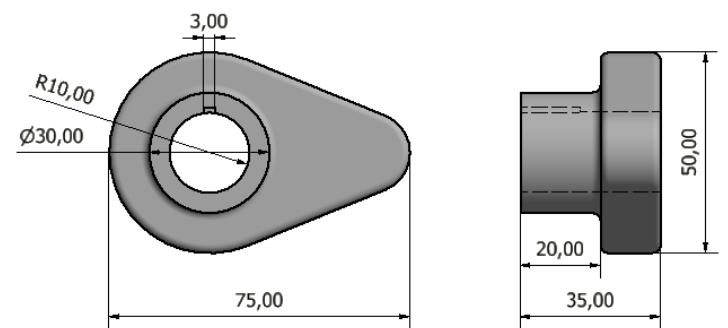

GAMBAR 2. Ukuran bender dalam milimeter

Mekanisme proses bending komponen rebar ditunjukkan pada Gambar 3.

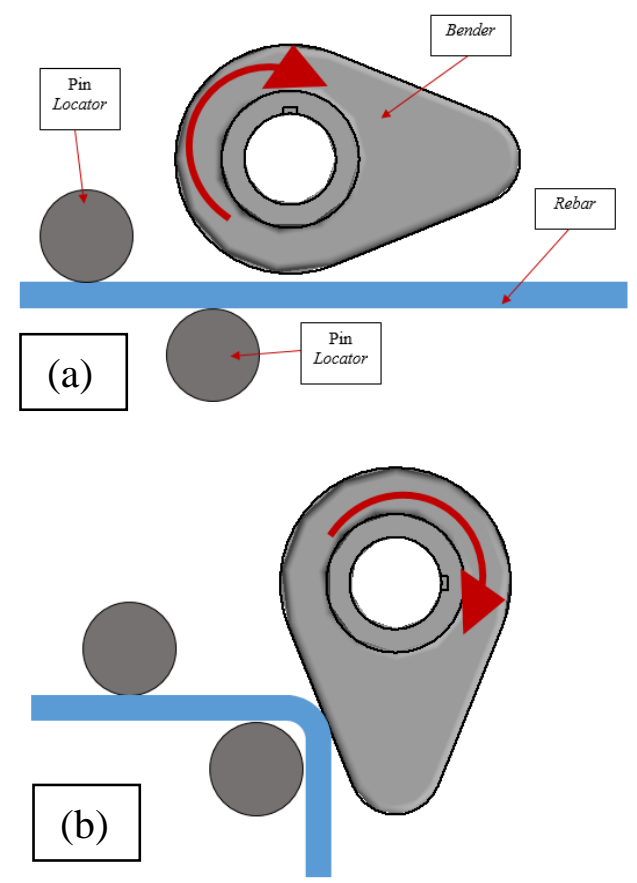

GAMBAR 3. Posisi bender (a) Sebelum proses bending dan (b) Setelah proses bending

Gambar 3a menunjukkan ilustrasi rebar yang bergerak menuju titik penekukan yang dikehendaki yang diatur melalui program pengendalian menggunakan mekanisme motor dan mikrokontroller. Saat mencapai lokasi penekukan, komponen bender akan bergerak searah jarum jam (Gambar 3b). Berdasarkan pergerakan bender pada Gambar 3, dapat dibuat diagram benda bebas yang menunjukkan arah gaya yang mengenai komponen bender seperti 
ditunjukkan pada Gambar 4. Tumpuan jepit (fix constraint) ditempatkan pada posisi ditempatkannya pen pada jalur masuknya poros, pen berfungsi sebagai penahan tetap agar komponen bender berada pada posisi rigid saat proses bending dilakukan.

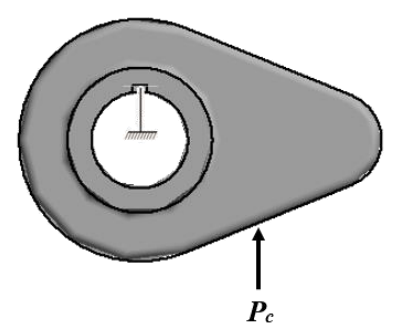

GAMBAR 4. Diagram benda bebas pada bender

Tahapan processing dilaksanakan dengan menggunakan data numerik hasil penelitian yang sudah dilakukan oleh peneliti sebelumnya. (Deepu et al., 2018) melakukan identifikasi terhadap gaya yang dibutuhkan untuk proses bending pada komponen rebar berdiameter 8 $\mathrm{mm}$. Berdasarkan penelitian tersebut diperoleh gaya yang digunakan untuk proses bending sebesar 196,13 N. Selain itu, perhitungan teoritis yang dilakukan oleh (Yaghmour et al., 2018) untuk proses bending menunjukkan gaya sebesar $840 \mathrm{~N}$ dibutuhkan untuk proses bending rebar berdiameter $8 \mathrm{~mm}$. Pada penelitian ini gaya pembebanan yang dipakai adalah sebesar $2520 \mathrm{~N}$ yang diperoleh dari perkalian nilai 840 $\mathrm{N}$ dengan konstanta faktor keamanan sebesar 3 seperti ditunjukkan pada Persamaan 1. Nilai pembebanan $(\mathrm{Pc})$ untuk tiap-tiap jenis material bender ditunjukkan pada Tabel 2. Penelitian uji tarik terhadap baja rebar yang dilakukan oleh (Subagiyo et al., 2017) bertujuan untuk mencari nilai yield strength baja tulangan (Tabel 1). Properti mekanis material bender mengacu pada data material yang terdapat di software Autodesk Inventor Library.

TABEL 1. Nilai rata-rata tegangan yield dan tegangan ultimate (Subagiyo et al., 2017)

\begin{tabular}{cccc}
\hline $\begin{array}{c}\text { Diameter } \\
\text { rebar } \\
\text { bersirip } \\
(\mathbf{m m})\end{array}$ & $\begin{array}{c}\boldsymbol{\sigma y} \\
\left(\mathbf{N} / \mathbf{m m}^{2}\right)\end{array}$ & $\begin{array}{c}\boldsymbol{\sigma u} \\
\left(\mathbf{N} / \mathbf{m m}^{2}\right)\end{array}$ & $\begin{array}{c}\boldsymbol{\varepsilon} \\
(\boldsymbol{\%})\end{array}$ \\
\hline$\varnothing 10$ & 523,65 & 675,88 & 40,9 \\
\hline$\varnothing 13$ & 475,48 & 651,06 & 39,3 \\
\hline$\varnothing 16$ & 484,55 & 649,35 & 36,1 \\
\hline$\varnothing 18$ & 422,49 & 610,50 & 38,4 \\
\hline
\end{tabular}

Nilai pembebanan (Pc) yang diberikan pada komponen bender dirumuskan dengan :

$\mathrm{Pc}=\mathrm{P}_{\mathrm{t}} * \mathrm{C}$

dengan $\mathrm{Pc}=$ Pembebanan pada bender $\left(\mathrm{N} / \mathrm{mm}^{2}\right)$, $\mathrm{P}_{\mathrm{t}}=$ tegangan teoritis, $\mathrm{C}=$ konstanta. Nilai ratarata tertinggi untuk $\sigma \mathrm{u}$ terdapat pada rebar berdiameter $10 \mathrm{~mm}$. Besarnya nilai ini dapat dipengaruhi oleh fenomena strain hardening yang muncul saat proses fabrikasi sirip pada komponen rebar.Sifat fisik material alumunium, mild steel, dan cat iron secara berurutan ditunjukkan oleh Tabel 3a, Tabel 3b, dan Tabel 3c.

TABEL 2. Nilai pembebanan $\left(\mathrm{Pc}_{\mathrm{c}}\right)$ untuk tiap jenis material bender

\begin{tabular}{lccc}
\hline Material & $\begin{array}{c}\mathbf{P}_{\mathbf{t}} \\
(\mathbf{N})\end{array}$ & $\begin{array}{c}\text { Konstanta } \\
(\mathbf{C})\end{array}$ & $\begin{array}{c}\text { Pc } \\
(\mathbf{N})\end{array}$ \\
\hline Alumunium & 840 & 3 & 2520 \\
\hline Mild Steel & 840 & 3 & 2520 \\
\hline Cast Iron & 840 & 3 & 2520 \\
\hline
\end{tabular}

TABEL 3a. Sifat fisik material Aluminum 6061

\begin{tabular}{lr}
\hline \multicolumn{1}{c}{ Material } & Alumunium $\mathbf{6 0 6 1}$ \\
\hline Density & $2,7 \mathrm{~g} / \mathrm{cm}^{3}$ \\
\hline Mass & $0,11 \mathrm{~kg}$ \\
\hline Area & $11289,6 \mathrm{~mm}^{2}$ \\
\hline Volume & $42412,9 \mathrm{~mm}^{3}$ \\
\hline Yield Strength & $275 \mathrm{MPa}$ \\
\hline Ultimate Tensile Strength & $310 \mathrm{MPa}$ \\
\hline Young's Modulus & $68,9 \mathrm{GPa}$ \\
\hline Poisson's Ratio & 0,33 \\
\hline Shear Modulus & $25,9023 \mathrm{GPa}$ \\
\hline
\end{tabular}

TABEL 3b. Sifat fisik material Mild Steel

\begin{tabular}{lr}
\hline \multicolumn{1}{c}{ Material } & \multicolumn{1}{c}{ Mild Steel } \\
\hline Density & $7,85 \mathrm{~g} / \mathrm{cm}^{3}$ \\
\hline Mass & $0,332942 \mathrm{~kg}$ \\
\hline Area & $11289,6 \mathrm{~mm}^{2}$ \\
\hline Volume & $42412,9 \mathrm{~mm}^{3}$ \\
\hline Yield Strength & $207 \mathrm{MPa}$ \\
\hline Ultimate Tensile Strength & $345 \mathrm{MPa}$ \\
\hline Young's Modulus & $220 \mathrm{GPa}$ \\
\hline Poisson's Ratio & 0,27 \\
\hline Shear Modulus & $86,2745 \mathrm{GPa}$ \\
\hline
\end{tabular}


TABEL 3c. Sifat fisik material Cast Iron

\begin{tabular}{lr}
\hline \multicolumn{1}{c}{ Material } & \multicolumn{1}{c}{ Cast Iron } \\
\hline Density & $7,15 \mathrm{~g} / \mathrm{cm}^{3}$ \\
\hline Mass & $0,30 \mathrm{~kg}$ \\
\hline Area & $11289,6 \mathrm{~mm}^{2}$ \\
\hline Volume & $42412,9 \mathrm{~mm}^{3}$ \\
\hline Yield Strength & $758 \mathrm{MPa}$ \\
\hline Ultimate Tensile & $884 \mathrm{MPa}$ \\
Strength & \\
\hline Young's Modulus & $120,5 \mathrm{GPa}$ \\
\hline Poisson's Ratio & 0,30 \\
\hline Shear Modulus & $46,3462 \mathrm{GPa}$ \\
\hline
\end{tabular}

Setting mesh dan parameter analisis tegangan yang digunakan pada simulasi pembebanan bender menggunakan software Autodesk Inventor 2020 ditunjukkan pada Tabel 4.

TABEL 4. Parameter analisis tegangan

\begin{tabular}{cc}
\hline Parameter & Keterangan \\
\hline Tipe simulasi & Static analysis \\
\hline Constraint & Fix constraint \\
\hline Force load & $2520 \mathrm{~N}$ \\
\hline Average element size & 0,01 \\
\hline Grading factor & 1,5 \\
\hline Safety factor & Berdasarkan yield \\
& strength \\
\hline Jumlah node & 717038 \\
\hline Jumlah elemen & 507873 \\
\hline
\end{tabular}

\section{HASIL DAN PEMBAHASAN}

Data numerik simulasi pembebanan menggunakan finite element analysis (FEA) pada software Autodesk Inventor 2020 ditunjukkan pada Tabel 5.

TABEL 5. Data numerik hasil simulasi FEA

\begin{tabular}{lccc}
\hline Material & $\begin{array}{c}\text { Von } \\
\text { Misses } \\
\text { Stress } \\
\text { Max } \\
(\mathbf{M P a})\end{array}$ & $\begin{array}{c}\text { Yield } \\
\text { Srength } \\
(\text { Mpa) }\end{array}$ & $\begin{array}{c}\text { Displacement } \\
(\mathbf{m m})\end{array}$ \\
& & \\
\hline Alumunium & 17,78 & 275 & 0,00765 \\
6061 & & & \\
Mild Steel & 17,49 & 207 & 0,00229 \\
Cast Iron & 17,62 & 758 & 0,00427 \\
\hline
\end{tabular}

Pembebanan sebesar $2520 \mathrm{MPa}$ yang terjadi pada komponen bender berbahan alumunium menunjukkan nilai tegangan von misses tertinggi yang timbul adalah sebesar 17,78 $\mathrm{MPa}$ dengan displacement $0,00765 \mathrm{~mm}$. Pola persebaran tegangan akibat reaksi dari pembebanan pada material alumunium 6061 ditunjukkan pada Gambar 5.

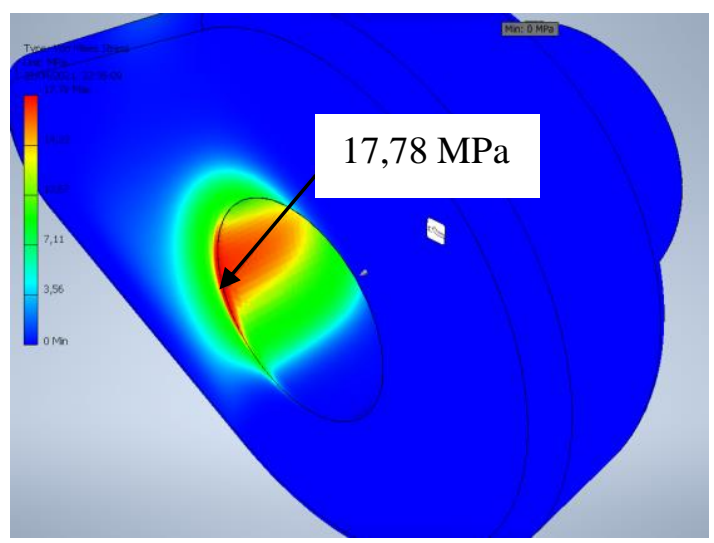

GAMBAR 5. Lokasi tegangan von misses maksimum pada material Alumunium 6061

Apabila dibandingkan dengan nilai yield strength material alumunium 6061 pada Tabel 3a, maka nilai tegangan yang muncul dari proses pembebanan masih berada pada zona elastis material tersebut sehingga defleksi sebesar $0,00765 \mathrm{~mm}$ tidak mengubah bentuk komponen bender secara permanen. Tinjauan terhadap bender yang terbuat dari material mild steel menampilkan sebaran tegangan yang ditunjukkan Gambar 6.

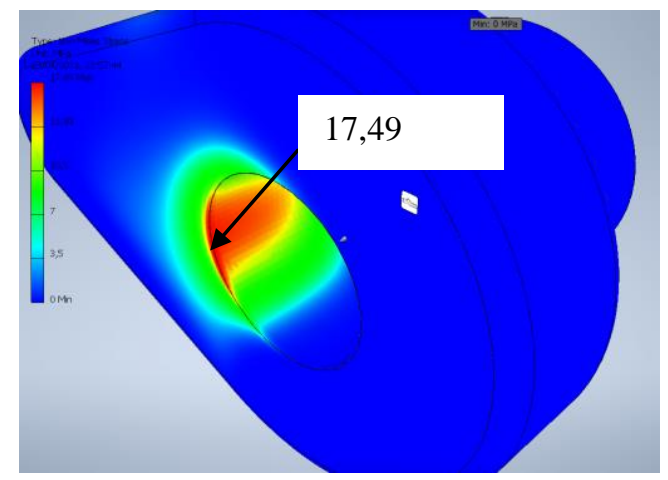

GAMBAR 6. Lokasi tegangan von misses maksimum pada material mild steel

Tegangan von misses maksimum yang terjadi pada bender berbahan mild steel sebesar 17,49 MPa. Nilai tersebut lebih rendah dibanding nilai yield strength mild steel sebesar $207 \mathrm{MPa}$. Hal ini menunjukkan, simulasi pembebanan sebesar $2520 \mathrm{MPa}$ pada material mild steel masih berada pada zona elastis, sehingga defleksi yang terjadi tidak mengubah bentuk komponen bender secara permanen. Material cast iron dengan nilai yield strength $758 \mathrm{MPa}$ dengan pembebanan $2520 \mathrm{MPa}$ secara simulasi menunjukkan pola yang sama dengan material 
alumunium 6061 dan mild steel. Tegangan von misses maksimum yang timbul akibat pembebanan adalah sebesar 17,62 $\mathrm{MPa}$ dengan nilai displacement $0,00427 \mathrm{~mm}$. Sebaran tegangan von misses untuk material cast iron ditunjukkan pada Gambar 7.

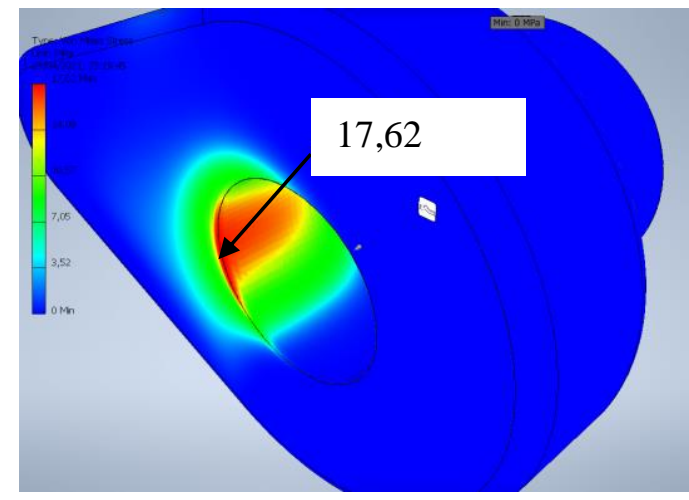

GAMBAR 7. Lokasi tegangan von misses maksimum pada material cast iron

Ketiga material memiliki lokasi tegangan von misses maksimal dan sebaran yang identik. Hal ini disebabkan oleh nilai numerik dari reaksi tegangan yang timbul akibat pembebanan berada pada rentang yang berdekatan (Tabel 5). Material cast iron yang memiliki nilai yield strength $758 \mathrm{MPa}$ dan sifat lebih getas dibandingkan alumunium dan mild steel menunjukkan respon nilai tegangan von misses yang identik dengan material mild steel dengan nilai yield strength 3,6 kali lebih rendah. Hal ini dapat disebabkan oleh pengaruh metode penghitungan distorsi energi yang ada pada software yang lebih sesuai untuk menghitung nilai tegangan von misses pada material elastis (Budynas \& Nisbett, 2011). Tinjauan lebih lanjut dengan metode eksperimen diperlukan untuk mengetahui respon nyata ketiga material penyusun komponen bender untuk memvalidasi hasil simulasi yang telah dilakukan.

\section{KESIMPULAN}

Simulasi pembebanan desain komponen bender yang terbuat dari material alumunium 6061, mild steel, dan cast iron menunjukkan respon tegangan von misses maksimum pada rentang 17-18 MPa. Tegangan von misses maksimum yang timbul bernilai lebih rendah dari nilai yield masing-masing material. Simulasi menunjukkan nilai safety factor pada desain bender sebesar 15 yang merupakan kategori aman untuk digunakan sebagai komponen penyusun mesin begel fabricator.

\section{DAFTAR PUSTAKA}

Afolabi, S. O., Oladapo, B. I., Ijagbemi, C. O., Adeoye, A. O. M., \& Kayode, J. F. (2019). Design and finite element analysis of a fatigue life prediction for safe and economical machine shaft. Journal of Materials Research and Technology, 8(1), 105-111. https://doi.org/10.1016/j.jmrt.2017.10.00 7

Budynas, R., \& Nisbett, J. K. (2011). Shigley's Mechanical Enginering Design (9th ed.). McGrawHill.

Deepu, S., Vishnu, R. S., Harish, M. T., \& Bhavani, R. R. (2018). An Experimental Study of Force Involved in Manual Rebar Bending Process. IOP Conference Series: Materials Science and Engineering, 310(1). https://doi.org/10.1088/1757899X/310/1/012050

Hariyanto, S.D., Papasi, R.G., Munthohani, G.R., Lanekri, I.T. and Sastika, I.P., 2020. Perancangan dan Fabrikasi Mesin Pengolah Ubi Kayu untuk Produksi Makanan Ringan Lanting Kapasitas 40 kg/jam. Quantum Teknika: Jurnal Teknik Mesin Terapan, 2(1), pp.38-46.

Shah, A. K., Kumar, N., Vignesh, M., \& Khanna, P. (2019). Design and fabrication of automatic rebar bending machine. 2018 International Conference on Computing, Power and Communication Technologies, GUCON 2018 , $1010-1013$. https://doi.org/10.1109/GUCON.2018.86 75068

Subagiyo, Sarjiyana, \& Wirawan. (2017). Analisis kekuatan tarik besi beton ulir berdasarkan diameternya. Seminar Nasional Terapan Teknologi 2016 POLINEMA, November 2016, 97-101.

Yaghmour, B. B., Qwasmh, S. H., \& Abuafifeh, I. F. (2018). Automatic Rebar Bending Machine to Form Rectangular Stirrups. 